\title{
OPIOID ANTAGONIST-INDUCED REGULATION OF THE $\mu$-OPIOID RECEPTOR EXPRESSION IN MCF-7 BREAST CANCER CELL LINE
}

\author{
Katarzyna Gach, Mariola Piestrzeniewicz, Jakub Fichna, Janusz Szemraj ${ }^{1}$, Anna Janecka \\ Laboratory of Biomolecular Chemistry, Medical University of Lodz, Lodz, Poland, ${ }^{1}$ Department of Medical \\ Biochemistry, Medical University of Lodz, Lodz, Poland \\ e-mail:ajanecka@zdn.am.lodz.pl
}

\begin{abstract}
Objective. In our earlier study we have demonstrated that MCF-7 cell line expresses all three opioid receptor types, $\mu, \delta$ and $\kappa$ (MOR, DOR and KOR, respectively), but predominantly MOR. Morphine, as well as endogenous MOR-selective agonists, endomorphin-1 and endomorphin-2 were shown to decrease MOR gene expression in MCF-7 cells. Opioid antagonist - naloxone produced the opposite effect, increasing MOR gene expression. In this study we investigated and compared the influence of several opioid antagonists of alkaloid structure ( $\beta$-funaltrexamine and naloxonazine) and of peptide structure: [Dmt $\left.{ }^{1}, \mathrm{D}-1-\mathrm{Nal}^{4}\right]$ endomorphin-2, [Dmt, D-2$\mathrm{Nal}^{4}$ ]endomorphin-1, and [Dmt, D-2-Nal ${ }^{4}$ ]endomorphin-2 on MOR up-/down-regulation and proliferation in MCF-7 cell line.

Methods. MCF-7 cells were incubated with opioids. The levels of MOR mRNA were assessed using quantitative real-time RT-PCR assay. Cell growth was measured by Mosmann tetrazolium salt assay.

Results. It was shown that all tested opioid antagonists produced up-regulation of MOR gene expression, but the strongest effect was observed with naloxonazine. However, none of the antagonists at concentrations as high as $10^{-4} \mathrm{M}$ showed any antiproliferative effects on MCF-7 cells, neither in the presence or absence of $\beta$-estradiol.

Conclusion. It seems that up- or down-regulation of MOR mRNA levels has no direct effect on cell proliferation.
\end{abstract}

Keywords: Gene expression - Opioid receptors - Endomorphins - Morphine - Naloxone

Opioid receptors, which belong to the superfamily of $\mathrm{G}$ protein-coupled receptors, have been pharmacologically classified into three major types, designated $\mu, \delta$, and $\kappa$ or MOR, DOR, and KOR, respectively, each distinct binding properties for various opioid ligands and with distinct localization and distribution (MINAMI and SAтоH 1995; SatoH and Minami 1995). Opioid receptors and their ligands were identified mostly in the central nervous system, but more recently their presence in different cancer cells was also reported (FICHNA and JANECKA 2004).
Various studies suggest that opioids elicit a variety of biological effects that appear to be independent of their analgesic properties and may affect cell survival or proliferation (TEGEDER and GeISSLINGER 2004). Since opioids are main drugs used for cancer pain management, understanding the impact of opioid drugs on cancer treatment besides pain control is extremely important. Several studies have shown a direct effect of morphine on cancer cells, but both growth-promoting and growth-inhibiting effects have been observed (TEGEDER et al. 2003; FAROOQUI et al.2007; LIN et al. 2007).

Corresponding author: Prof. Anna Janecka, PhD; Laboratory of Biomolecular Chemistry, Medical University of Lodz; Mazowiecka 6/8, 92-215 Lodz, Poland. Phone: +48 426790450 ext. 259; Fax: +48 4267842 77; e-mail: ajanecka@zdn.am.lodz.pl 
Other studies have shown that not only morphine, but also the opioid antagonist naloxone can act directly on MCF-7 tumor cells and inhibit breast cancer growth in mice, however, the mechanism of this action remains unknown (GUPTA et al. 2002; TEGEDER et al. 2003; Lin et al. 2007). Recently FAROOQUI et al. (2006) examined the cellular and molecular mechanism of naloxone antagonism of estrogen-dependent MCF-7 cell growth. Their results indicated that MOR might immunoprecipitate with estrogen receptor in the MCF7 cells incubated with naloxone. Thus naloxone was shown to modulate tumor cell growth indirectly through the estrogen receptor. The authors postulated that naloxone-like compounds can be developed as novel therapeutics for breast cancer therapy.

In our previous study GACH et al. (2008) we have demonstrated that MCF-7 cell line expresses all three opioid receptor types, but predominantly MOR. Morphine, as well as endogenous MOR-selective ligands, endomorphin-1 and endomorphin-2 were shown to decrease MOR gene expression in MCF-7 cell line. Naloxone produced the opposite effect, increasing MOR gene expression.

In this study we investigated and compared the influence of several opioid antagonists of alkaloid, as well as peptide structure, on MOR up-/down-regulation and proliferation of MCF-7 cells.

\section{Materials and Methods}

Reagents. The MCF-7 cell line was kindly provided by Dr.Marek Rozalski (Institute of Pharmaceutical Biochemistry, Medical University of Lodz, Poland).

All standard cell culture reagents were obtained from Gibco-BRL (Bethesda, MD, USA). Trizol reagent was obtained from Invitrogen Life Technologies Inc. (Rockville, MD, USA). Primer pairs were designed using PrimerExpress software (Applied Biosystems, Foster City, CA, USA) and purchased from Integrated DNA Technologies (Coralville, IN, USA). Morphine sulfate, naloxone hydrochloride, naloxonazine dihydrochloride and $\beta$-funaltrexamine hydrochloride were purchased from Sigma-Aldrich (St.Louis, MO, USA). Peptide antagonists were synthesized in our laboratory using a standard solid-phase method, described previously FICHNA et al. (2007). The structures of antagonists are shown in Fig. 1.

Cell culture. The MCF-7 human breast adenocarcinoma cells were cultured in Dulbecco's minimal essential medium (DMEM) supplemented with glutamine
(2 mM), gentamycin $(5 \mu \mathrm{g} / \mathrm{ml})$ and and $10 \%$ heat-inactivated fetal bovine serum. Cells were maintained at $37{ }^{\circ} \mathrm{C}$ in a $5 \% \mathrm{CO}_{2}$ atmosphere and grown until $80 \%$ confluent.

Quantitative real-time RT-PCR assay. The expression of the MOR gene and B-actin gene(a house-keeping gene) was quantified by real-time RT-PCR using ABI Prism 7000 Sequence Detection System (Applied Biosystems, Foster City, CA, USA). Total cellular mRNA $(1 \mu \mathrm{g})$ was extracted from $10^{6} \mathrm{MCF}-7$ cells using Trizol reagent and a single-step purification protocol Chomczynski and SACCHI (1987). RNA pellets were dissolved in water and their concentration and purity were determined by spectrophotometric readings at 260 and $280 \mathrm{~nm}$. The relative amounts of the specific mRNAs were quantified by RT-PCR.

Extracted RNA was processed directly to cDNA using Oligotex kit (Qiagen, Chatsworth, CA, USA). To create standard curves, $2.5,2.0,1.5,1.0,0.5$, and 0.25 $\mu \mathrm{l}$ of the cDNA for $\beta$-actin and the target gene, were amplified in triplicate. Likewise, $2 \mu \mathrm{l}$ of isolated cDNA for $B$-actin, as well as $2 \mu \mathrm{l}$ of cDNA for each primer/ probe combination, was also amplified in triplicate. Each sample, containing $0.3 \mu \mathrm{M}$ of the respective forward and reverse primers and a fluorescent probe, was made up to $50 \mu \mathrm{l}$ using $\mathrm{qPCR}^{\mathrm{TM}}$ Mastermix for SYBR Green I (Eurogentec S.A., Liege Science Park, Belgium) and amplified in a separate 96-well plate. All samples were incubated at $50{ }^{\circ} \mathrm{C}$ for $2 \mathrm{~min}$ and at 95 ${ }^{\circ} \mathrm{C}$ for $10 \mathrm{~min}$, and than cycled at $95{ }^{\circ} \mathrm{C}$ for $30 \mathrm{~s}, 56^{\circ} \mathrm{C}$ for $1 \mathrm{~min}$, and $72{ }^{\circ} \mathrm{C}$ for $1 \mathrm{~min}$ for 40 cycles. SYBR Green I fluorescence emission data were captured and mRNA levels were quantified using the critical threshold $\left(\mathrm{C}_{\mathrm{t}}\right)$ value. Analyses were performed with an ABI Prism 7000 Sequence Detection System (Applied Biosystems). Controls without reverse transcription and with no template cDNA were inclouded with each assay. To compensate for the variations in input mRNA amounts and efficiency of reverse transcription, $\beta$-actin mRNA was quantified and results were normalized to these values. Relative gene expression levels were obtained using the $\Delta \Delta \mathrm{C}_{\mathrm{t}}$ method WINER et al. (1999). Amplification specific transcripts were further confirmed by obtaining melting curve profiles.

Incubation with opioids. The MCF-7 cells were seeded in $25 \mathrm{~mL}$ cell culture flasks in standard growth medium at a density of $2.5 \times 10^{5}$ cells/flask. After 24 $\mathrm{h}$, the growth medium was replaced by a fresh growth medium, supplemented with the opioids in desired concentration. Cells incubated without opioid ligands were 


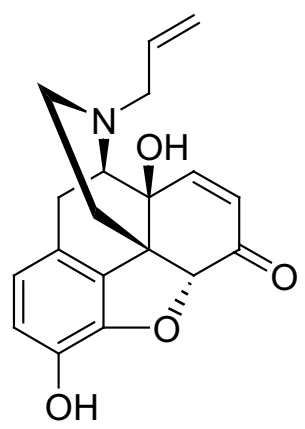

$\mathrm{Nal}$<smiles>COC(=O)/C=C/C(=O)NC1CC[C@@]2(O)[C@H]3Cc4ccc(O)c5c4[C@@]2(CCN3C2CC2)[C@H]1O5</smiles>

$\beta$-FNA

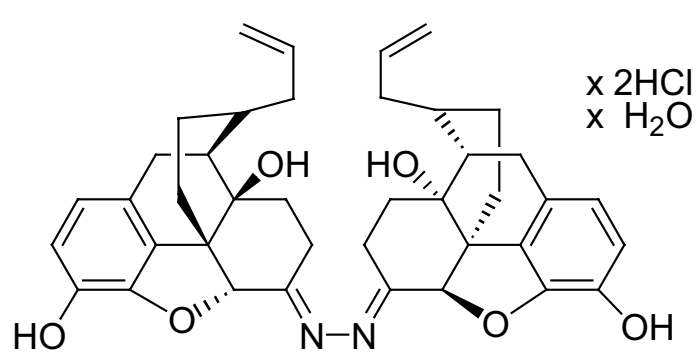

Nxz<smiles>Cc1cc(O)cc(C)c1C[C@H](N)C(=O)N1CCC[C@H]1C(=O)N[C@@H](Cc1ccccc1)C(=O)N[C@@H](Cc1cccc2ccccc12)C(N)=O</smiles>

I<smiles>Cc1cc(O)cc(C)c1C[C@H](N)C(=O)N1CCC[C@H]1C(=O)N[C@@H](Cc1c[nH]c2ccccc12)C(=O)N[C@@H](Cc1ccc2ccccc2c1)C(N)=O</smiles>

II<smiles>Cc1cc(O)cc(C)c1C[C@H](N)C(=O)N1CCC[C@H]1C(=O)N[C@@H](Cc1ccccc1)C(=O)N[C@@H](Cc1ccc2ccccc2c1)C(N)=O</smiles>

III

Fig. 1 The structure of antagonists used in the study. 


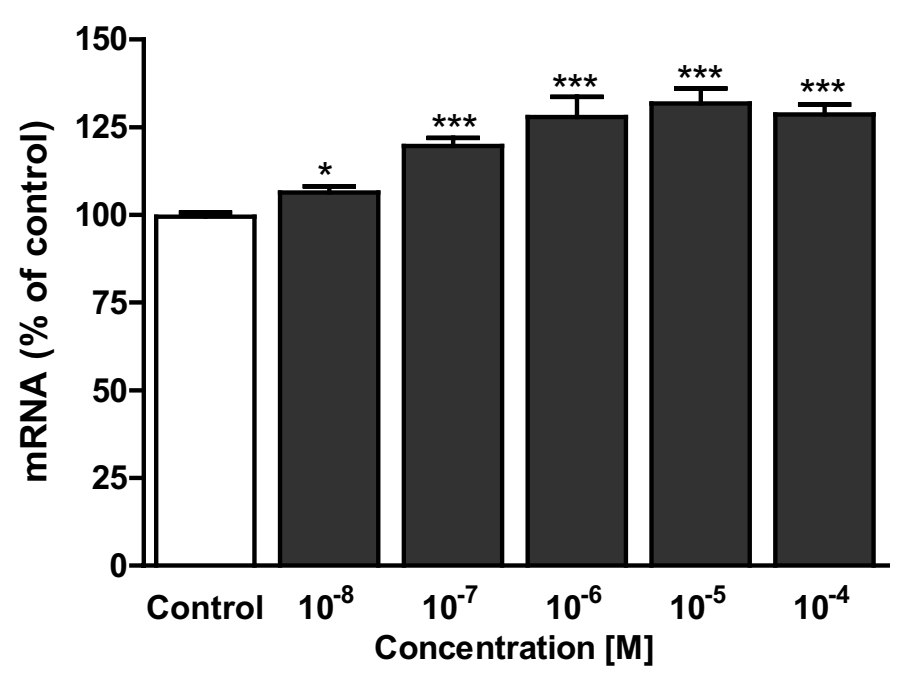

Fig. 2 Concentration-response regulation of MOR mRNA level in MCF-7 cells incubated with naloxone for 48 h, as measured by quantitative real-time RT-PCR analysis. Data represent mean \pm SD of three independent experiments performed in duplicate. Statistical significance was assessed using a one-way ANOVA and a post-hoc multiple comparison Student-NewmanKeuls test. Statistical significance compared with control (untreated cells, $100 \%$ ) was as follows: $*=\mathbf{p}<0.05 ; * * *=\mathbf{p}<0.001$.

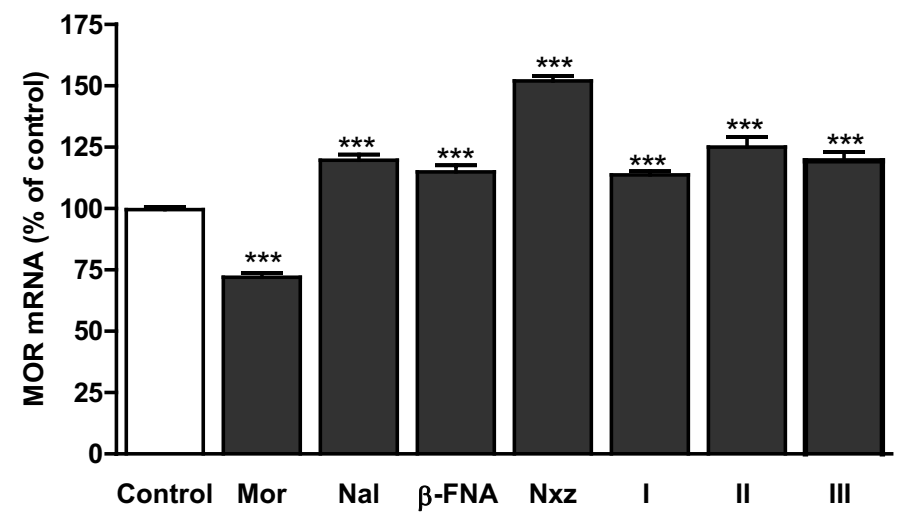

Fig. 3 Quantitative real-time RT-PCR analysis of the effect of: opioid agonist, morphine (Mor), and opioid antagonists, naloxone (Nal), b-funaltrexamine (B-FNA), naloxonazine (Nxz) and peptide antagonists I-III (all at $10^{-7} \mathrm{M}$ ) incubated for $48 \mathrm{~h}$ with MCF-7 cells on MOR mRNA expression. Data represent mean \pm SD of three independent experiments performed in duplicate. Statistical significance was assessed using one-way ANOVA followed by the Student-Newman-Keuls test $(* * *=\mathbf{p}<0.001$ significantly different from untreated cells regarded as control, $100 \%$ ).

Table 1

PCR primers used for relative quantitative reverse transcriptase-PCR assays of mRNA.

\begin{tabular}{lcc}
\hline Target gene & & \\
\hline \multicolumn{4}{c}{ Forward primers } & Reverse primers \\
MOR & 5' GTCCTTTATGCATTTCTGGATGAAAAC 3' & 5' CTGGAAGCAGAAACTGCTCCGTTG 3' \\
ß-Actin & 5' GTGGGGCGCCCCAGGCACCA 3' & 5' CTCCTTAATGTCACGCACGATTTC 3' \\
\hline
\end{tabular}


used as control. After $48 \mathrm{~h}$ incubation, the cells were washed twice with Dulbecco's phosphate-buffered saline (Sigma-Aldrich) to remove added opioids and then harvested by trypsinization. The cells were frozen and kept at $-80^{\circ} \mathrm{C}$ for further experiments.

Cell proliferation. $\mathrm{MCF}-7$ cells were routinely grown in Dulbecco's minimal essential medium, supplemented with glutamine $(2 \mathrm{mM})$, gentamycin $(5 \mu \mathrm{g} /$ $\mathrm{mL})$ and $10 \%$ heat-inactivated fetal bovine serum. Optionally, $\beta$-estradiol $\left(10^{-8} \mathrm{M}\right)$ or insulin $(10 \mu \mathrm{g} / \mathrm{mL})$ were added to the medium. Cells were maintained at $37^{\circ} \mathrm{C}$ in a humidified atmosphere of $5 \% \mathrm{CO}_{2}$ in air.

Cells were seeded in 24-well ELISA plates at an initial density of $20 \times 10^{3}$ cells/well. All compounds were added to cultures $24 \mathrm{~h}$ after seeding. Cells were grown for additional $72 \mathrm{~h}$. Cell growth was measured by the tetrazolium salt assay for cell viability as described by Mosmann (1983). Briefly, cells were incubated for $2 \mathrm{~h}$ at $37{ }^{\circ} \mathrm{C}$ with MTT [3-(4,5-dimethylthiazol-2-yl0-2,5diphenyltetrazolium bromide] and the metabolically active cells reduced the dye to blue formazan product. The absorbance was measured at $540 \mathrm{~nm}$ and compared against a standard curve of known numbers of MCF-7 cells. All experiments were performed in triplicate.

Statistical evaluation was performed using Prism 4.0 (GraphPad Software Inc., San Diego, Calif, USA). The data were expressed as means \pm SD. Differences between groups were assessed by a one-way ANOVA followed by a post-hoc multiple comparison StudentNewman-Keuls test. A probability level of 0.05 or lower was considered statistically significant.

\section{Results}

Effect of opioid antagonists on MOR mRNA expression in MCF-7 cells. MCF-7 cells were treated for $48 \mathrm{~h}$ with various concentrations of naloxone, ranging from $10^{-8}$ to $10^{-4} \mathrm{M}$. Total RNA was then extracted and the expression level of MOR mRNA was determined by quantitative real-time PCR. The concentration-dependent increase of mRNA expression was observed at lower concentrations (Fig. 2). For further studies with MOR antagonists $10^{-7} \mathrm{M}$ concentration was chosen.

The MCF-7 cells were incubated for $48 \mathrm{~h}$ with MOR antagonists (Fig. 1): non-selective naloxone (Nal), MORselective $\beta$-funaltrexamine ( $\beta$-FNA), $\mathrm{MOR}_{1}$-selective naloxonazine (Nxz) and three MOR-selective peptide antagonists, Dmt-Pro-Phe-D-1-Nal-NH $\mathrm{NH}_{2}$ (I), Dmt-Pro-TrpD-2-Nal-NH 2 (II), and Dmt-Pro-Phe-D-2-Nal-NH 2 (III), all at the concentration of $10^{-7} \mathrm{M}$. For comparison opio- id agonist morphine, at the same concentration, was also used. The effect of these compounds on MOR mRNA expression was quantified using quantitative real-time RT-PCR. As shown in Fig.3, treating the MCF-7 cells with these antagonists up-regulated MOR mRNA levels as compared with untreated cells (considered as control, $100 \%$ ), but to a different degree. The most pronounced up-regulation of MOR was observed when the cells were treated with Nxz (150\% of control), while weaker effect was produced by Nal, $\beta$-FNA and peptide analogs (115-125\% of control). Opioid agonist, morphine, produced an opposite effect - down-regulation of MOR mRNA expression.

Effect of opioid antagonists on proliferation of MCF-7 cells. Proliferation of MCF-7 cells was studied when antagonists were added to the culture medium directly or after pretreatment of the cells with Bestradiol or/and insulin. Cell proliferation was not inhibited by incubation of the cells with any of MOR antagonists used in this study at a concentration range $10^{-8}$ to $10^{-4} \mathrm{M}$. The addition of $\beta$-estradiol or insulin to the growth medium did not influence the results.

\section{Discussion}

Whereas the pharmacology and function of opioids have been extensively characterized in the central nervous system, little is known about their effect on nonneuronal systems. Opioid effects on tumor growth in vivo or cancer cell growth in vitro are very controversial.

Most of the studies concerning the role of opioids in cancer cell growth deal with morphine. Many cancer patients suffer from severe pain and are given morphine in high doses. GuPTA et al. (2002) showed recently that morphine promotes growth of breast cancer xenografts in nude mice by increasing angiogenesis. The proangiogenic activity of morphine was also observed by FAROOQUi et al. (2007). Tumor-promoting effects of morphine have been found in mice that received an injection with leukemia or sarcoma cells IsHIKAWA et al. (1993). However, inhibitory effect of morphine on MCF-7 cell proliferation at high concentrations $\left(\geq 10^{-5}\right.$ M) was also reported TEGEDER et al. (2003).

On the other hand, TEGEDER et al. (2003) showed inhibition of MCF-7 cell proliferation with naloxone, however at high concentrations $\left(25 \times 10^{-5} \mathrm{M}\right)$. FAROOQUI et al. (2006) reported that naloxone $\left(10^{-7} \mathrm{M}\right)$ decreased $\mathrm{MCF}-7$ proliferation in the presence and absence of $\beta$-estradiol.

In our earlier studies we have demonstrated the presence of MOR in the MCF-7 breast cancer cells, at pro- 
tein (FICHNA et al. 2005) and mRNA level (GACH et al. 2008). We have also shown that selective MOR agonists, morphine and endomorphins concentration- and time-dependently down-regulated MOR mRNA levels, while naloxone produced a slight increase in the MOR gene expression.

Here, we compared the effect of naloxone and several other opioid MOR-selective antagonists on MOR mRNA levels in MCF-7 cells. We have found that all tested antagonists up-regulated MOR gene expression and the most pronounced effect was observed for $\mathrm{MOR}_{1}$-selective antagonist, naloxonazine.
However, none of the antagonists at concentration as high as $10^{-4} \mathrm{M}$ showed any antiproliferative effects on MCF-7 cells, neither in the presence or absence of $\beta$-estradiol. It seems that up- or down-regulation of MOR mRNA levels has no direct effect on proliferation.

\section{Acknowledgements}

This work was supported by the grants from the Medical University of Lodz (No 502-11-460, 502-11461, and 503-1099-1).

\section{References}

Chomczynski P, SAcchi N: Single-step method of RNA isolation by acid guanidinium thiocyanate- phenol - chloroform extraction. Anal Biochem 162, 156-159, 1987

Faroogui M, Geng ZH, Stephenson EJ, Zaveri N, Yee D, Gupta K: Naloxone acts as an antagonist of estrogen receptor activity in MCF-7 cells. Mol Cancer Ther 5, 611-620, 2006

Faroogui M, Li Y, Rogers T, Poonawala T, Griffin RJ, Song CW, Gupta K : COX-2 inhibitor celecoxib prevents chronic morphine-induced promotion of angiogenesis, tumour growth, metastasis and mortality, without compromising analgesia. Br J Cancer: 97, 1523-1531, 2007

FichNA J, JANECKA A: Opioid peptides in cancer. Cancer Metast Rev 23, 351-366, 2004

Fichna J, Krajewska U, Rozalski M, Mirowski M, Janecka A: Characterization of the [ ${ }^{125}$ I] endomorphin-2 binding sites in the MCF7 breast cancer cell line. Peptides. 26, 295-299, 2005

Fichna J, do-Rego J-C, Chung NN, Lemieux C, Schiller PW, Poels J, Vanden Broeck J, Costentin J, Janecka A: Synthesis and characterization of potent and selective $\mu$-opioid receptor antagonists, $\left[\mathrm{Dmt}^{1}, \mathrm{D}-2-\mathrm{Nal}^{4}\right]$ endomorphin-1 (antanal-1) and [Dmt ${ }^{1}$, D-2-Nal $\left.{ }^{4}\right]$ endomorphin-2 (antanal-2). J Med Chem 50, 512-520, 2007

Gach K, Piestrzeniewicz M, Fichna J, Stefanska B, Szemraj J, Janecka A: Opioid-induced regulation of the $\mu$-opioid receptor gene expression in the MCF-7 breast cancer cell line. Biochem Cell Biol 86, 217-226, 2008

Gupta K, Kshirsagar S, Chang L, Schwartz R, Law PY, Yee D, Hebbel RP: Morphine stimulates angiogenesis by activating proangiogenic and survival-promoting signaling and promotes breast tumor growth. Cancer Res 62 , 4491-4498, 2002

Ishikawa M, TANnO K, KaRno A, TAKAYANAGI Y, SASAKI K: Enhancement of tumor growth by morphine and its possible mechanism in mice. Biol Pharm Bull 16, 762-766, 1993

Lin X, Li Q, Wang YJ, Ju YW, Chi ZQ, Wang MW, Liu JG: Morphine inhibits doxorubicin-induced reactive oxygen species generation and nuclear factor kappaB transcriptional activation in neuroblastoma SH-SY5Y cells. Biochem J: 406, 215-221, 2007

Minami M, Satoh M: Molecular biology of the opioid receptors: structures, functions and distributions. Neurosci Res 23, $121-145,1995$

Mosmann T: Rapid colorimetric assay for cellular growth and survival: application to proliferation and cytotoxicity assays. J Immunol Methods 65, 55-63, 1983

Satoh M, Minami M: Molecular pharmacology of the opioid receptors. Pharmacol Ther 68, 343-364, 1995

Tegeder I, Geisslinger G: Opioids as modulators of cell death and survival-unraveling mechanisms and revealing new indications. Pharmacol Rev: 56, 351-369, 2004

Tegeder I, Grosch S, Schmidtro A, Häussler A, Schmidt H, Niederberger E, Scholich K, Geisslinger G: G proteinindependent G1 cell cycle block and apoptosis with morphine in adenocarcinoma cells: involvement of p53 phosphorylation. Cancer Res: 63, 1846-1852, 2003

Winer J, Jung CK, Shackel I, WiLliams PM: Development and validation of real-time quantitative reverse transcriptase-polymerase chain reaction for monitoring gene expression in cardiac myocytes in vitro. Anal Biochem 270, 41-49, 1999 